\title{
O credenciamento do laboratório antidopagem: ciência e política na luta contra o doping no esporte
}

\author{
The accreditation of the anti-doping laboratory: science and politics in the fight against \\ doping in sport
La acreditación del laboratorio antidopaje: ciencia y política en la lucha contra el dopaje en el deporte

Daniel Giordani Vasques ${ }^{a *}$ (D), Ekain Zubizarreta Zuzuarregi ${ }^{b}$ (D) Marco Paulo Stigger $^{c}$ (D)

Palavras-chave: Antidopagem; Credenciamento; Política; Ciência.

Keywords: Anti-doping; Accreditation; Politics; Science.

Palabras-clave: Antidopaje; Acreditación; Política; Ciencia.

\begin{abstract}
RESUMO
A pesquisa social sobre doping e a luta contra ele cresceu nos últimos anos, porém sua distribuição é desigual. O objetivo é descrever como os interesses da WADA e do governo brasileiro para ter o laboratório preparado para os Jogos de 2016 afetaram a luta antidopagem. Adotamos procedimentos etnográficos para analisar a suspensão, descredenciamento e recredenciamento do LBCD (2013-2015). Com ajuda da sociologia pragmática, visualizaram-se associações e interesses dos atores. Especificamente, retratou-se como a WADA conseguiu pressionar o governo por meio do descredenciamento de 2013 e, a partir das ações e associações do governo, como ela foi flexível para recredenciar um laboratório em condições inadequadas, a fim de mantê-lo atuante para os Jogos de 2016.
\end{abstract}

\begin{abstract}
Social research on doping and anti-doping has grown in recent years. However, its distribution is uneven. The objective is to study how WADA and Brazilian government for having an operational laboratory affected anti-doping. We adopted an ethnographic approach to describe the processes of suspension, revocation and re-accreditation of LBCD (2013-2015). Using pragmatic sociology concepts, it is possible to identify actors' associations and interests. Specifically, the paper will show that WADA managed to pressure the government through the 2013 revocation - forcing it to act and to associate with other actors - but it was then flexible to re-accredit a laboratory in inadequate conditions, in order to have it operational for 2016 Games.
\end{abstract}

\section{RESUMEN}

La investigación social sobre antidopaje ha crecido en los últimos años, sin embargo, la repartición es desigual. El objetivo es describir cómo los intereses de AMA y del gobierno brasileño de tener un laboratorio para los JJOO de 2016 afectaron la lucha antidopaje. Adoptamos métodos etnográficos para analizar los procesos de suspensión, desacreditación y reacreditación del LBCD (2013-2015). Es posible identificar las asociaciones e intereses de los actores. Específicamente, se relata cómo AMA logró presionar al gobierno con la desacreditación y que, tras las acciones y asociaciones posteriores del gobierno, cómo fue flexible a la hora de volver a acreditar el laboratorio en condiciones inadecuadas, a fin de mantener el laboratorio operativo para los Juegos.

\footnotetext{
aUniversidade Federal do Rio Grande do Sul, Colégio de Aplicação, Departamento de Expressão e Movimento. Porto Alegre, RS, Brasil. bInstitut des Sciences Sociales du Politique, Universidade Paris Nanterre. Paris, França.

'Universidade Federal do Rio Grande do Sul, Programa de Pós-graduação em Ciências do Movimento Humano. Porto Alegre, RS, Brasil.
}

\footnotetext{
*Autor correspondente:

Daniel Giordani Vasques

E-mail: dgvasques@hotmail.com
} 


\section{INTRODUÇÃO}

A pesquisa em ciências sociais sobre doping e a luta contra o doping cresceu consideravelmente nos últimos anos. Refletem esse crescente interesse por parte da academia as publicações em revistas internacionais de alto impacto (por exemplo, Hanstad et al., 2008; Waddington, 2010) e livros dedicados ao doping (por exemplo, Demeslay, 2013; Dimeo e Møller, 2018; Krieger, 2016). No Brasil, o número especial desta revista dedicado ao doping (Soares e Daólio, 2005) e os artigos de Silveira e Rigo (2015) e Vasques et al. (2021) indicam o interesse no tema. No entanto, a distribuição desta pesquisa é desigual: as questões éticas, dispositivos antidopagem (Mcnamee e Møller, 2011) e a aplicação de regulamentos em nível nacional (Hanstad et al., 2010) têm sido objeto de muitas pesquisas. Do ponto de vista metodológico, conforme argumentado por Trabal e Zubizarreta (2020), os trabalhos empíricos são menos numerosos e, entre estes, são minoria aqueles que utilizam uma abordagem etnográfica.

Nesse contexto, o propósito desse artigo é descrever como os interesses da WADA e do governo brasileiro afetaram a luta antidopagem para ter um laboratório preparado para os Jogos de 2016, o que foi analisado a partir de seus processos de suspensão, descredenciamento e reacreditação ${ }^{1}$. A análise da atividade do laboratório brasileiro não só permite compreender o funcionamento desta parte do sistema antidopagem, mas também explicar como a luta antidopagem é afetada pelos interesses de atores políticos e esportivos. A WADA², uma organização internacional que lidera a luta contra o doping, aspira ser uma instituição que atue independentemente das autoridades públicas e do movimento olímpico (Demeslay, 2013; Hanstad et al., 2008). Para isso, se propõe ao uso de métodos científicos e protocolos técnicos precisos. No entanto, nossa análise mostra que nem sempre as ações ocorrem dessa maneira e que a ação antidoping não é alheia aos interesses dos atores dos universos político e esportivo.

O artigo está estruturado da seguinte forma: primeiro, recorre-se a uma breve apresentação das reflexões teóricas que nos levaram a priorizar a abordagem da sociologia pragmática francesa e apresentam-se os métodos; após, descrevemos a criação do $\mathrm{LBCD}^{3}$ e a estruturação do sistema antidopagem brasileiro; em seguida, a suspensão e o descredenciamento do laboratório em 2013 são analisados; por fim, apresenta-se

1 Credenciamento e acreditação são sinônimos no campo para descrever o processo de concessão dos laboratórios antidopagem para atuar.

2 World Anti-Doping Agency.

3 Laboratório Brasileiro de Controle de Dopagem. o processo de recredenciamento do laboratório e as associações com a $\mathrm{ABCD}^{4}$ e a $\mathrm{CBF}^{5}$.

\section{QUADRO TEÓRICO}

A luta contra o doping está imersa em um processo de harmonização global liderado pela WADA desde sua criação em 1999 (Demeslay, 2013). A Agência Mundial, formada por representantes dos Estados e do movimento olímpico, é responsável por criar os dispositivos legais que as autoridades públicas e federações internacionais devem aplicar, bem como estabelecer a lista de produtos proibidos, os protocolos de ação e de credenciamento, suspensão ou desacreditação dos laboratórios antidopagem.

Os laboratórios são parte fundamental do complexo sistema antidopagem, pois analisam amostras de urina ou sangue de atletas para identificar o uso de substâncias proibidas. O sistema é amparado por sanções para atletas (Dimeo e Møller, 2018), as quais são sustentadas por resultados de análises químicas de alta precisão científica realizadas em laboratórios. A WADA é responsável por determinar quais laboratórios podem analisar amostras. Para isso, a Agência, como parte de seu sistema de supervisão laboratorial denominado External Quality Assessment Scheme (WADA, 2021a), envia frequentemente aos laboratórios amostras sobre as quais já sabe os resultados, denominados testes cegos ou duplos-cegos. As análises destas amostras funcionam como testes de controle de qualidade do laboratório, que pode estar ciente do teste ou não.

Cada resultado de amostra analisada pelo laboratório é inserido em um sistema online ${ }^{6}$ controlado pela Agência Mundial. Assim, se o laboratório errar em alguma análise, pode ser suspenso ou descredenciado, a depender do tipo de erro (artigo 4.6.4 do ISL; WADA, 2021b). A suspensão dura cerca de seis meses, enquanto o descredenciamento pode durar dois anos, apesar destes períodos de tempo serem variáveis. Uma vez descredenciado, um conjunto de controles, análises e protocolos devem ser seguidos pelo laboratório para conseguir o recredenciamento. No início de 2021, havia 26 laboratórios antidopagem ativos dos 30 existentes no mundo; quatro estavam suspensos (WADA, 2021c).

Apesar disso, pesquisadores em ciências sociais têm demonstrado pouco interesse em estudar laboratórios antidoping. Temos conhecimento apenas do trabalho realizado por Krieger $(2015,2016)$ sobre a criação de laboratórios antidopagem e a estruturação de um sistema de acreditação, primeiro pela IAAF e pelo COI, e depois, nos anos 2000, pela WADA. Existem, também, alguns trabalhos que tratam da questão dos interesses privados e seus efeitos na luta contra o doping.

\footnotetext{
4 Autoridade Brasileira de Controle de Dopagem.

5 Confederação Brasileira de Futebol.

6 ADAMS.
} 
Esses trabalhos mostram como o combate ao doping não está isento de interesses privados que afetam a atividade da Agência, especialmente os interesses do movimento olímpico, liderado pelo COI. Eles identificaram que os representantes do COI dividem espaços decisórios com representantes dos Estados, mas possuem maior capacidade decisória devido a alguns fatores como, por exemplo, aos sistemas de rodízio dos governantes e à unidade entre os integrantes do movimento olímpico (Demeslay, 2013; Zubizarreta e Demeslay, 2021). Essa predominância nos espaços de tomada de decisão afeta a neutralidade e independência da WADA na tomada de decisões para criar mecanismos legais ou aplicar sanções (Henne, 2010; Wagner, 2010).

Importa destacar que a atividade antidopagem dos laboratórios, técnica e complexa, aproveita os últimos avanços técnico-científicos, uma vez que as decisões podem ter consequências graves para os atletas, pelo que estes têm de ser devidamente justificados. Sendo, então, os laboratórios partes de um campo técnico, científico e controlado, até que ponto as decisões da WADA sobre credenciamentos poderiam ser afetadas por interesses políticos?

Para responder a essa questão, nos sustentamos em Latour (2019) cuja pesquisa sobre o trabalho científico mostra como essa atividade nunca está isenta de interesses, desejos ou vontades. Nessa perspectiva a produção científica é um híbrido, no sentido que mistura elementos da política (interesses, motivações, associações) a elementos científicos (química, física, testes). Para ele, a separação de ciência e política é uma construção moderna que, de fato, nunca existiu. O que existem no universo científico são purificações, onde um desses lados é apagado, ocultado, o que normalmente ocorre com as motivações e interesses na produção científica. A forma como é descrita a atividade dos laboratórios antidopagem se aproxima, portanto, de uma ciência purificada, que considera que os resultados antidoping são um trabalho científico puro, isento de interesses, desejos e vontades. No entanto, escândalos como o da Romênia ou da Rússia (Arribas, 2016; Brown, 2019) deixam claro que essa ideia nada mais é do que uma ilusão. No caso específico da WADA, como dar conta da hibridez (Latour, 2019) da existência de interesses além do aspecto científico, sem ter acesso a espaços de decisão?

\section{MATERIAL E MÉTODOS}

Uma alternativa é a análise de um ou mais momentos de prova (épreuve), que são aqueles que revelam a complexidade de desvios e ajustes que compõem o fato. Chateauraynaud (2007) define prova como um momento de incerteza sobre um estado de coisas; assim, o momento de prova pode conduzir a uma mudança no estado delas. Latour (2012) traz o exemplo da pane ao afirmar que esta é a expressão mais pedagógica da prova. Um laboratório, um objeto técnico torna-se visível como um objeto sociotécnico quando há neles uma pane: de simples ele se torna múltiplo, de unificado torna-se desarmônico, de rápido torna-se lento. Uma parte dos elementos constitutivos que o mantinham funcionando vem à tona, e eles se tornam visíveis.

Nesse sentido, as suspensões ou desacreditações respondem por erros no funcionamento dos laboratórios e são momentos oportunos para analisar tanto a atividade dos laboratórios como a atividade de acompanhamento/ supervisão da WADA. Por um lado, os especialistas da WADA têm que justificar devidamente a suspensão, já que o laboratório poderá recorrer da decisão. Por outro lado, os laboratórios precisam aprimorar seus procedimentos e métodos de análise e justificar as decisões tomadas a fim de obter a aprovação do grupo de especialistas para recuperar seu credenciamento o mais breve. Propomos assim, através da análise da suspensão e descrédito da LBCD em 2013 e do processo de recredenciamento, analisar a atividade dos atores antidopagem envolvidos, de forma a apresentar a hibridez na construção da antidopagem.

Para Latour (2000, p. 178-199), interesse - do latim 'inter-esse' - é aquilo que está entre os atores e os seus objetivos, criando uma tensão que fará os atores selecionarem apenas aquilo que, para eles, os auxilie a alcançar esses objetivos. Para aliar atores, Latour traz a noção da translação de interesses, que é a mudança de termos e de linguagem nos interesses dos atores. São cinco formas de translação: "eu quero o que você quer"; "eu quero, por que você não quer?"; "se você desviasse um pouquinho"; "remanejando interesses e objetivos"; e "tornar-se indispensável". Foi a partir dessas noções que procuramos visualizar como o novo laboratório ficou pronto para os Jogos.

A obtenção dos dados dessa pesquisa ocorreu a partir da busca por controvérsias, momentos importantes nos quais as caixas-pretas da ciência estão em abertura (Latour, 2019). É a exposição de argumentos, ideias e propostas em sentidos opostos produzidas pelas controvérsias que permite que o pesquisador visualize os atores e seus interesses. Os dados foram produzidos por meio de uma etnografia multisituada, de modo a observar ações cujos objetos de estudo perpassam muitas localidades (Marcus, 2001).

Dessa forma, o primeiro autor dessa pesquisa realizou imersões no mundo da antidopagem de fevereiro de 2016 a agosto de 2017, ao obter formação e atuar como um agente de controle de dopagem em eventos nos quais fez uso da observação participante. Foram entrevistados 16 atores da antidopagem, grupo composto por secretários, coordenadores, funcionários da $A B C D$, do $L B C D$ e da CBF, além de outros trabalhadores, desse universo que concordaram em participar da pesquisa. As entrevistas foram efetuadas presencialmente em diferentes locais (Brasília, Florianópolis, Lisboa, Porto Alegre, Rio de Janeiro e São Paulo), tendo em conta a disponibilidade dos interlocutores. Por fim, também 
foram analisados documentos públicos desse universo. Essa pesquisa foi aprovada pelo Comitê de Ética sob o parecer 2.081.732.

\section{RESULTADOS E DISCUSSÃO}

\section{CRIAÇÃO DO LBCD E ESTRUTURAÇÃO DO SISTEMA ANTIDOPAGEM BRASILEIRO}

Análises de amostras de atletas para o sistema antidopagem são realizadas pelo LBCD desde 1988, que até 2015 se denominava LADETEC. Ele foi criado para a Copa América de futebol de 1989, está situado e é parte da Universidade Federal do Rio de Janeiro (UFRJ). Ele foi o único laboratório brasileiro acreditado pelo COI (2002-2004) e pela WADA (2004-2013) e, quando da realização dessa pesquisa era o único laboratório sul-americano acreditado.

A ABCD, criada em 2011, entrou em funcionamento em 2014. Anteriormente, os controles antidopagem eram organizados pelas federações e pela Agência Brasileira Antidoping, que durou até 2012 e estava associada ao comitê olímpico nacional. Porém, esta instituição não era uma organização nacional antidopagem (NADO).

\section{3: SUSPENSÃO DO LBCD}

O laboratório brasileiro viu sua acreditação suspensa em agosto de 2013 por falhar em detectar substâncias em testes cegos e duplo-cegos da WADA (WADA, 2013a). Porém, o planejamento do governo para os Jogos de 2016 sempre incluiu o laboratório, sendo que ele estava presente inclusive nos termos assinados com o $\mathrm{COI}^{7}$.

A suspensão revelou as dificuldades que o sistema tinha para funcionar como, por exemplo, os problemas para adquirir as amostras mínimas para os espectrômetros, para a importação de material biológico e para a compra de máquinas de tecnologia mais recente. Segundo Antônio Geertz, funcionário do LBCD, os erros nas análises seriam devidos às mudanças de tecnologia que ocorrem nesse mundo dos equipamentos antidopagem, as quais o laboratório brasileiro não conseguiu implementar a tempo. Para adequação do LBCD às novas tecnologias dos "usos da ciência" (Latour, 2019) no laboratório, foram necessários recursos públicos, disposição e convencimento político, normas e formas de compra de materiais específicos.

Vários movimentos do LBCD para garantir a acreditação estavam ocorrendo em $2013^{8}$. No entanto, sem dar explicações adicionais, a WADA anunciou a

7 Os termos de compromisso entre governo brasileiro e COI para os Jogos incluíram, segundo Wurtz, a criação da NADO brasileira e a reestruturação do laboratório na cidade dos Jogos.

8 Importar produtos para alimentar espectrômetros, mudar procedimentos de aprovação pela Agência Nacional de Vigilância Sanitária (ANVISA), etc. desacreditação efetiva do laboratório apenas 19 dias depois de ter suspendido a sua acreditação ( 27 de agosto - WADA, 2013b), processo que normalmente ocorre seis meses após a suspensão?

\section{AÇÃO-REAÇÃO: A DESACREDITAÇÃO COMO UM GATILHO PARA FAZER ATUAR}

Na única explicação pública oferecida pela WADA, ela afirmou que confiou na análise de seus especialistas para revogar o credenciamento. Segundo relatos, a decisão seria influenciada pelos interesses esportivos do $\mathrm{CO}$ que tem muito poder dentro da Agência. O COl estava interessado em garantir que teria um laboratório maior, de uma nova forma, operando nos Jogos, caso contrário teria que planejar a análise das amostras de outra forma e trabalhar com laboratórios de outros países, o que aumentaria consideravelmente as obras e os custos de realização do programa de controle de doping nos Jogos. Então, de acordo com essa narrativa, a Agência teria descredenciado o laboratório brasileiro para gerar um escândalo de proporção mundial: sendo o laboratório do país que sediaria os Jogos, era importante acuar o governo brasileiro e forçá-lo a responder com verba e vontade política para construir o laboratório novo:

Quando o laboratório foi suspenso em agosto de 2013 pela WADA, o descredenciamento foi político. Eles exerceram um poder político pra pôr fogo no governo brasileiro pro laboratório sair. Funcionou do ponto de vista de pressão da WADA, mas o desgaste no governo foi grande. Pra eles, funcionou. Fizeram uso disso pra botar pressão, terror... e botou. (Entrevista com João Pedro Wurtz ${ }^{10}$ - interlocutor $\left.A B C D\right)$.

Como veremos, a estratégia da WADA funcionou, dado que nesse mesmo ano o governo injetou 188 milhões de reais para a criação do novo prédio para o LBCD. Assim, uma parte dele ficou pronta em junho de 2014 para começar o processo de reacreditação. Ademais, o LBCD se aliou à $A B C D$, que estava inserida no Ministério do Esporte e, assim, na política governamental de preparação do país para as Olimpíadas, o que colocou o LBCD na agenda política dos Jogos.

\section{ASSOCIAÇÃO COM A ABCD PARA ENTRAR NA AGENDA POLÍTICA E ARRECADAR FUN- DOS}

"Assustaram-se as autoridades" com essa desacreditação, afirmou um interlocutor. As discussões e as ações do governo com o laboratório se deram

\footnotetext{
9 A suspensão é automática a partir de um erro, mas o descredenciamento é uma decisão do grupo de especialistas.

${ }^{10}$ Os nomes dos interlocutores foram alterados. Entrevista realizada em Brasília em 11/08/2017 com duração de 04h51min.
} 
mediadas por um ator da $A B C D$, que havia se aliado a um funcionário do $L B C D$ para buscarem conjuntamente a constituição da Agência e a reacreditação do laboratório. Como ele havia se aproximado da Casa Civil, e desse "bolo nobre" de ações do governo para os Jogos Olímpicos - e a associação da ABCD com o LBCD trazia também um maior peso para instituições antidopagem na tomada de decisões do governo sobre essas questões -, Wurtz acordou que ele mesmo deveria tratar das necessidades das duas instituições. Ele descreve, em detalhes, seu processo de aproximação com o funcionário do $L B C D$, bem como apresenta associações suas com a Casa Civil:

A construção do laboratório envolveu muito a $A B C D$. Quando eles foram embora [WADA na reunião de 2009], eu fui atrás de entender o laboratório [...]. Fui lá na porta do tal laboratório pra falar com um camarada [...]. Aí formei um grupo de trabalho no Ministério do Esporte, que envolveu alguém da Rio2016, [...] nós, Ministério do Esporte, laboratório, ANVISA, receita federal por causa de alfândega [...]. Evidentemente, depois que eu tinha a Casa Civil do meu lado, a minha vida ficou sempre melhor. (Entrevista com João Pedro Wurtz).

As associações entre Wurtz e Geertz fizeram a antidopagem ocupar um espaço de maior importância na agenda do governo para os Jogos. Ele mesmo confirma essa associação com o LBCD ao afirmar que "desde o começo, pela relação que eu estabeleci com o Antônio, de confiança mútua [...], nós começamos a levar [atuar]". A aproximação entre uma NADO e um laboratório, porém, não é bem-vista pela WADA, já que há informações da NADO que não podem chegar ao laboratório - por exemplo, o nome dos atletas. A Agência Mundial, no entanto, tolerou essa aproximação entre os dois, especialmente porque esses laços auxiliaram a pôr o LBCD na agenda política brasileira. Wurtz afirma ter sido questionado pela WADA sobre essa proximidade:

\begin{abstract}
A WADA começa a achar que isso pode ser um problema. Que o responsável pela NADO [estivesse] enfiado no laboratório, ou resolvendo o problema do laboratório. Isso criou um aparente conflito de interesses [...]. Se vocês querem um laboratório pros Jogos Olímpicos, eu vou entregar, com esse esforço de todo mundo. E aí eles aceitaram. (Entrevista com João Pedro Wurtz).
\end{abstract}

A trajetória do dirigente mostrou como é possível aliar atores de distintas instituições e aumentar a influência política. Em termos de política pública, a $A B C D$ era parte do Ministério do Esporte e, assim, os atores do governo/ Ministério do Esporte/ABCD tinham como objetivo criar uma política (pública) nacional antidopagem. Para isso, interessava (no sentido latouriano) se associar com o LBCD, com a ANVISA, a Casa Civil; e, ao mesmo tempo, se afastar de atores da antidopagem que não eram bem-vistos pela WADA, por estarem mais próximos às federações esportivas, de quem a política antidopagem deveria ser independente. Essas associações resultaram na aprovação, naquele mesmo ano, de uma 'injeção' de dinheiro público no laboratório.

Aí, já sem tempo hábil sensato para preparar o
laboratório, mas pior sem um "Plano B" que tivesse
a mínima chance de sucesso, voltaram-se a nós
[laboratório] compensando o tempo com uma
montanha de recursos, como se fosse possível comprar
o tempo perdido. Coube ao laboratório, quase que por
milagre, reverter essa situação. Parte desse "milagre"
na verdade foi uma atitude estratégica da UFRJ.
Sabendo como se passam as coisas neste país, a Reitoria
da UFRJ partiu para antecipar etapas da construção
do prédio novo. Assim sendo, inúmeras etapas de
prazos longos já estavam sendo antecipadas desde
2008 . Definição e homologação do terreno, projeto
de remoção de árvores e compensação ambiental,
sondagem do terreno, projeto e execução do canteiro
de obras, projeto básico, etc., foram adiantados pela
UFRJ, mesmo sem a garantia de que o Governo Federal
investiria nolaboratório. Essa estratégia salvou o Brasil
do maior vexame relacionado aos Jogos Olímpicos e
Paralímpicos, pois seria a primeira vez na história em
que o país-sede não teria um laboratório operando no
local para garantir resultados liberados em $\mathbf{2 4}$ horas.
(Entrevista com Antônio Geertz - interlocutor LBCD). (Entrevista com Antônio Geertz ${ }^{11}$ - interlocutor LBCD).

O governo federal entendeu que o laboratório era, além de uma promessa que o governo havia feito quando da decisão da sede dos Jogos em 2009, parte uma política pública de Estado. Tendo em vista os Jogos e a pressão exercida pelo descredenciamento, o governo agiu "com uma montanha de recursos" para, segundo Geertz, salvar o país "do maior vexame". Geertz ainda ressalta a importância da associação do laboratório com a UFRJ, fundamental para o atendimento do objetivo de construir o prédio novo.

\section{O PROCESSO DE RECREDENCIAMENTO}

O interesse do LBCD era recuperar a acreditação. A WADA queria que isso ocorresse nas instalações novas e até junho de 2015, para poder analisar amostras dos eventos-teste realizados no Rio de Janeiro como preparação para os Jogos. A reacreditação foi concedida em 13 de maio de 2015 (Brasil, 2021), após a WADA realizar uma série de testes cegos e duplo-cego e auditorias, mesmo com a execução inacabada da obra do novo prédio do laboratório, o que obrigou que esses processos ocorressem em espaços que já se encontravam com as obras concluídas.

Isso levou a outro "milagre", pois tivemos de recuperar essa acreditação em apenas sete meses, pois um sexto do prédio do laboratório só foi entregue em julho de 2014 e a WADA exigiu que o processo de reacreditação ocorresse nas instalações novas! Assim sendo, nos

\footnotetext{
${ }^{11}$ Entrevista realizada no Rio de Janeiro em 27/07/2017.
} 
esprememos no meio do canteiro de obras para realizar todos os testes e auditorias de reacreditação. Assim em 18/08/2014 iniciou-se o processo de reacreditação, o qual envolveu cinco conjuntos de amostras cegas e três auditorias comprimidas em sete meses. A reacreditação foi concedida em 13 de maio de 2015.

Ao menos aí a WADA fez vista grossa, pois poderia ter jogado duro e exigido o prédio todo pronto antes de iniciar o processo. Creio que não o fizeram por acreditar que nessas condições nós jamais conseguiríamos nos reacreditar, o que encerraria o problema deles, mas transformaria os Jogos Olímpicos e Paralímpicos Rio 2016 em um fiasco. Algo que não Ihes dizia respeito, mas sim ao Governo Brasileiro que não cumprira suas promessas e, em última análise, ao $\mathrm{COl}$ que era o responsável pelo evento. (Entrevista com Antônio Geertz).

O novo prédio ocuparia um espaço enorme dentro da UFRJ, com equipamentos modernos e a segurança e vigilância reforçadas, em contraste com o prédio anterior, que tinha pouco espaço para a demanda de Jogos Olímpicos. Porém, naquele momento de reacreditação as condições não eram adequadas. Segundo Geertz, somente um sexto do prédio estava pronto e os testes para a reacreditação ocorreram com os funcionários se espremendo "no meio do canteiro de obras". Tal "vista grossa" da WADA para conceder a acreditação nessas condições mostra o objetivo da Agência em ter um laboratório em ação na cidade-sede, e para isso era necessário que ele atuasse naquele momento. Para além de critérios técnicos, os dados mostram que os interesses dos atores, sobretudo da WADA, foram parte das decisões técnico-científicas. Ou seja, os atores empregaram argumentos científicos para atingir seus objetivos, mostrando uma purificação (Latour, 2019). Ao usar argumentos da ciência e ocultar a política, a antidopagem visa a se purificar e purificar o esporte.

Para Latour (2012), nas relações entre os atores ambos são entendidos como agentes do processo social, pois agem mutuamente, interferindo e influenciando o comportamento um do outro. Assim, um ator não é meramente alvo de outro, mas sim de um "amplo conjunto de entidades que enxameiam em sua direção" (p.75). Nesse sentido, a flexibilidade na exigência do cumprimento das regras por um ator é resultante da ação de diversos outros atores, e não uma decisão individual. No caso em tela, a flexibilidade da WADA foi concedida a partir de uma translação de interesses na direção do LBCD/governo brasileiro, tendo em vista o calendário apertado para os Jogos de 2016.

Uma vez obtida a acreditação, foi necessária outra associação subsequente, desta vez com o objetivo de estabilizar o número de amostras a serem analisadas. O objetivo do laboratório, para ter estabilidade e não perder novamente a acreditação, era aumentar o número de amostras que analisaria. Apesar de ter liberdade para enviar para qualquer laboratório do mundo, a ABCD envia todas as suas amostras para o LBCD, que é uma instituição pública que se espera manter em funcionamento.

A CBF, por sua vez, a instituição que mais realizava controles antidoping no país, levava as suas amostras para serem analisadas em laboratórios de fora do país desde a desacreditação do LBCD. Segundo membros da $\mathrm{CBF}$, os quais foram entrevistados no curso dessa pesquisa ${ }^{12,}$ as amostras eram normalmente levadas para os laboratórios de Los Angeles (Estados Unidos) ou de Colônia (Alemanha), já que o LBCD se mostrava instável e as análises ali efetuadas custavam mais caro. Segundo Bernardo da Silva ${ }^{13}$, funcionário do LBCD, há laboratórios que praticam preços mais baixos por realizarem maior quantidade de análises do que o LBCD. Ou seja, o preço praticado pelo laboratório brasileiro poderia ser mais baixo, caso instituições de outros países enviassem amostras.

Os custos e a desacreditação haviam distanciado a CBF do LBCD. No entanto, o grupo ABCD-LBCD aproximou-se da CBF com o interesse de aumentar as amostras e baixar o custo, o que poderia atrair instituições antidopagem de países vizinhos a enviar amostras. A CBF retomou o envio de parte das amostras ao laboratório brasileiro em 2017; a associação ABCDLBCD-CBF permitiu ao laboratório certa estabilidade.

\section{CONCLUSÃO}

Essa pesquisa teve como objetivo estudar os processos de suspensão, descredenciamento e reacreditação do laboratório antidopagem brasileiro ao longo da preparação para os Jogos de 2016. O estudo mostrou que em 2009 o governo brasileiro se comprometeu a ter um laboratório antidopagem funcionando para os Jogos Olímpicos, a partir da escolha do Rio de Janeiro como cidade-sede - o laboratório existia desde 1989, no entanto, se fazia necessária sua ampliação e melhoramento dos equipamentos. Passados quatro anos, em 2013, pouco havia mudado, quando o laboratório teve erro de análise e foi suspenso pela WADA e 19 dias após, foi desacreditado. Nossa análise, que se baseia no estudo do procedimento utilizado pela WADA, defende que a desacreditação da WADA foi afetada consideravelmente pelos interesses do COI.

Os momentos de suspensão e desacreditação da LBCD (2013) motivaram no Brasil uma série de ações e associações por parte dos principais atores da antidopagem. Estas, que tinham como objetivo a

12 Entrevistas realizadas com Otávio Santos e Roberto Sorento, realizadas em 12/04/2017 e 18/08/2017, em Florianópolis e São Paulo, com duração de 01h10min e $01 \mathrm{~h} 23 \mathrm{~min}$, respectivamente.

${ }^{13}$ Entrevista realizada no Rio de Janeiro em 27/07/2017 com duração de 39 minutos. 
recuperação da reacreditação, envolveram Geertz e Wurtz, ABCD, LBCD, ANVISA, Casa Civil, Ministério do Esporte, e possibilitaram entender o laboratório (e a $A B C D$ ) como parte de uma política nacional antidopagem, a qual era dever do Estado. Após 188 milhões de reais serem investidos, o laboratório foi construído, equipado e posto à prova. Em 13 de maio de 2015 a reacreditação foi concedida, porém, para isso, a WADA fez "vista grossa" ao aceitar a colaboração estreita entre a NADO e o laboratório e ao conceder a reacreditação em meio a um canteiro de obras. Em condições normais o LBCD não teria obtido a reacreditação, porém os Jogos batiam à porta e a temporalidade desta vez foi determinante para a flexibilização das regras.

O resultado foi positivo do ponto de vista da WADA, já que ela atingiu seu objetivo, exerceu seu poder de persuasão e fez o governo federal agir. Também foi positivo para o laboratório e, em escala maior, para o governo brasileiro, pois atingiu seu objetivo de ter o laboratório credenciado e podendo atuar nos Jogos, algo prometido desde em 2009. Por fim, a aliança do laboratório com a CBF tornou-se uma estratégia para a manutenção do LBCD.

Em termos sociológicos, pode-se dizer que a pressão exercida pela WADA para forçar uma reação das autoridades públicas brasileiras e a conseguinte flexibilização para outorgar novamente a acreditação, mostram a hibridez de ciência e política nas decisões do combate ao doping. As decisões que a WADA pretende mostrar como científicas e independentes, e, assim, alheias às preferências e interesses (esportivos, políticos ou econômicos) dos numerosos atores envolvidos, são purificações típicas do universo científico que se diz moderno e reiteram o emprego pelas instituições esportivas de argumentos da ciência para atingir seus interesses.

\section{FINANCIAMENTO}

$$
\text { Bolsa Capes. }
$$

\section{CONFLITOS DE INTERESSE} interesse.

Os autores declaram não haver conflitos de

\section{REFERÊNCIAS}

Arribas C. Assim a Rússia fazia desaparecer o doping positivo de seus melhores atletas: sistema de controle empregado em 2011 e 2015 burlava o controle das agências internacionais [Internet]. 2016 [citado em 2021 Ago 9]. Disponível em: https://brasil.elpais.com/ brasil/2016/07/18/deportes/1468863237_248396.html

Brasil. Ministério da Cidadania. Secretaria Especial do Esporte. [Internet]. 2021 [citado em 2021 Ago 9]. Disponível em: http://arquivo.esporte.gov.br/index. php/ultimas-noticias/209-ultimas-noticias/50731- especialistas-comemoram-a-reacreditacao-dolaboratorio-brasileiro-de-controle-de-dopagem

Brown A. Romanian NADO instructed Lab to cover up positive tests [Internet]. 2019 [citado em 2021 Ago 9]. Disponível em: https://www.sportsintegrityinitiative.com/romaniannado-instructed-lab-to-cover-up-positive-tests/

Chateauraynaud F. La contrainte argumentative. Les formes de l'argumentation entre cadres délibératifs et puissances d'expression politiques. Revue Européenne Des Sciences Sociales. 2007;45(136):129-48. http://dx.doi.org/10.4000/ ress.93.

Demeslay J. L'institution mondiale du dopage: sociologie d'un processus d'harmonisation. Paris: PÉTRA; 2013.

Dimeo P, Møller V. The anti-doping crisis in sport. The antidoping crisis in sport. London: Routledge; 2018. http:// dx.doi.org/10.4324/9781315545677

Hanstad DV, Skille EA, Loland S. Harmonization of anti-doping work: myth or reality? Sport Soc. 2010;13(3):418-30. http://dx.doi.org/10.1080/17430431003588036.

Hanstad DV, Smith A, Waddington I. The establishment of the World Anti-doping Agency: a study of the management of organizational change and unplanned outcomes. Int Rev Sociol Sport. 2008;43(3):227-49. http://dx.doi. org/10.1177/1012690208100552.

Henne K. WADA, the promises of law and the landscapes of antidoping regulation. Polit Leg Anthropol Rev. 2010;33(2):306-25. http://dx.doi.org/10.1111/j.15552934.2010.01116.x.

Krieger J. Dope Hunters: the influence of scientists on the global fight against doping in sport, 1967-1992. Commonground: Champaign; 2016. http://dx.doi.org/10.18848/978-161229-835-1/CGP.

Krieger J. The history of the establishment of an accreditation scheme for olympic doping laboratories from 1972 to 1985. In: Pardo R, Aja TG, Irureta-Goyena P, editors. El Fenómeno del Dopaje. Madrid: Universidad Politécnica de Madrid; 2015. p. 193-204.

Latour B. Ciência em ação: como seguir cientistas e engenheiros sociedade afora. São Paulo: UNESP; 2000.

Latour B. Jamais fomos modernos: ensaio de antropologia simétrica. São Paulo: Editora 34; 2019.

Latour B. Reagregando o social: uma introdução à teoria do ator-rede. Salvador: Edufba; 2012.

Marcus G. Etnografia en/del sistema mundo: el surgimiento de la etnografia multilocal. Alteridades (El Parque). 2001;11(22):111-27.

Mcnamee M, Møller V. Doping and anti-doping policy in sport ethical, legal and social perspectives. London: Routledge; 2011. http://dx.doi.org/10.4324/9780203807262.

Silveira VT, Rigo LC. O programa Passaporte Biológico: considerações sobre o governo dos atletas. Movimento. 2015;21(2):495-506. http://dx.doi.org/10.22456/19828918.48211.

Soares CL, Daólio J. Editorial. Rev Bras Ciênc Esporte. 2005;27(1):7-8.

Trabal P, Zubizarreta E. A proposal for theoretical and empirical extension of the sociology of anti-doping. Perform Enhanc 
Health. 2020;8(2-3):100177. http://dx.doi.org/10.1016/j. peh.2020.100177.

Vasques DG, Myskiw M, Trabal P, Stigger MP. A antidopagem em face das demandas da agência mundial: uma etnografia da conformidade em ação. Movimento. 2021;27:e27035. http://dx.doi.org/10.22456/1982-8918.111756.

WADA: World Anti-Doping Agency. WADA suspends the accreditation of the Rio de Janeiro Laboratory [Internet]. 2013a [citado em 2013 Ago 9]. Disponível em: https:// www.wada-ama.org/en/media/news/2013-08/wadasuspends-the-accreditation-of-the-rio-de-janeirolaboratory

WADA: World Anti-Doping Agency. WADA revokes accreditation of Rio de Janeiro laboratory [Internet]. 2013b [citado em 2013 Ago 27]. Disponível em: https://www.wada-ama.org/ en/media/news/2013-08/wada-revokes-accreditation-ofrio-de-janeiro-laboratory

WADA: World Anti-Doping Agency. Accreditation process [Internet]. 2021a [citado em 2021 Ago 27]. Disponível em: https://www.wada-ama.org/en/what-we-do/sciencemedical/laboratories/accreditation-process
WADA: World Anti-Doping Agency. ISL-International Standard for Laboratories [Internet]. 2021b [citado em 2021 Ago 21]. Disponível em: https://www.wada-ama.org/en/resources/ laboratories/international-standard-for-laboratories-isl

WADA: World Anti-Doping Agency. Accredited laboratories [Internet]. 2021c [citado em 2021 Ago 9]. Disponível em: https://www.wada-ama.org/en/what-we-do/sciencemedical/laboratories/accredited-laboratories

Waddington I. Surveillance and control in sport: a sociologist looks at the WADA whereabouts system. Int J Sport Policy Polit. 2010;2(3):255-74. http://dx.doi.org/10.1080/19406 940.2010 .507210

Wagner U. The world anti-doping agency, power and law beyond the state. In:Wagner $U$, Storm RK, Hoberman J, editors. Observing sport: modern system theoretical approaches. Schorndorf: Hofmann-Verlag; 2010. p. 77-102.

Zubizarreta E, Demeslay J. Power relationships between the world anti-doping agency andnational anti-doping agencies and their effects on anti-doping. Performance Enhancement \& Health, 2021;8(4). https://doi. org/10.1016/j.peh.2020.100181. 